\title{
Low hemoglobin is associated with poor functional outcome after non-traumatic, supratentorial intracerebral hemorrhage
}

\author{
Jennifer Diedler*+1, Marek Sykora†1,2, Philipp Hahn¹, Kristin Heerlein', Marion N Schölzke1, Lars Kellert1, Julian Bösel', \\ Sven Poli ${ }^{1}$ and Thorsten Steiner ${ }^{1}$
}

\begin{abstract}
Introduction: The impact of anemia on functional outcome and mortality in patients suffering from non-traumatic intracerebral hemorrhage $(\mathrm{ICH})$ has not been investigated. Here, we assessed the relationship between hemoglobin (HB) levels and clinical outcome after ICH.

Methods: One hundred and ninety six patients suffering from supratentorial, non-traumatic ICH were extracted from our local stroke database (June 2004 to June 2006). Clinical and radiologic computed tomography data, HB levels on admission, mean $\mathrm{HB}$ values and nadir during hospital stay were recorded. Outcome was assessed at discharge and 3 months using the modified Rankin score (mRS).

Results: Forty six (23.5\%) patients achieved a favorable functional outcome (mRS $\leq 3$ ) and 150 (76.5\%) had poor outcome (mRS 4 - 6) at discharge. Patients with poor functional outcome had a lower mean HB (12.3 versus $13.7 \mathrm{~g} / \mathrm{dl}, P$ $<0.001)$ and nadir HB (11.5 versus $13.0 \mathrm{~g} / \mathrm{dl}, P<0.001)$. Ten patients $(5.1 \%)$ received red blood cell (RBC) transfusions. In a multivariate logistic regression model, the mean HB was an independent predictor for poor functional outcome at three months (odds ratio (OR) $0.73,95 \%$ confidence interval (CI) $0.58-0.92, P=0.007$ ), along with National Institute of Health Stroke Scale (NIHSS) at admission (OR 1.17, 95\% Cl 1.11-1.24, $P<0.001$ ), and age (OR 1.08, 95\% Cl 1.04 - 1.12, $P<$ 0.001).

Conclusions: We report an association between low HB and poor outcome in patients with non-traumatic, supratentorial ICH. While a causal relationship could not be proven, previous experimental studies and studies in brain injured patients provide evidence for detrimental effects of anemia on brain metabolism. However, the potential risk of anemia must be balanced against the risk of harm from red blood cell infusion.
\end{abstract}

\section{Introduction}

Intracerebral hemorrhage ( $\mathrm{ICH})$ accounts for approximately 10 to $15 \%$ of acute strokes and is still associated with a mortality up to 30 to $50 \%$ [1]. ICH volume, neurological status on admission, age above 80 years and the presence of intraventricular blood were found to be strong predictors of 30 -day mortality [2]. Around $50 \%$ of the patients require mechanical ventilation [3] and most are admitted to an ICU [4]. A study including medical and surgical ICU patients found a high incidence of ane-

\footnotetext{
* Correspondence: jennifer.diedler@med.uni-heidelberg.de

1 Department of Neurology, University of Heidelberg, Im Neuenheimer Feld 400, 69120 Heidelberg, Germany

+ Contributed equally

Full list of author information is available at the end of the article
}

mia in critically ill patients and the nadir hemoglobin (HB) level of less than $9 \mathrm{~g} / \mathrm{dl}$ as a predictor of increased mortality and length of hospital stay [5]. At the same time, the number of red blood cell (RBC) transfusions a patient received was independently associated with increased mortality. The current literature supports the idea that many critically ill patients tolerate HB levels as low as $7 \mathrm{~g} / \mathrm{dl}$ and that a liberal transfusion strategy may in fact lead to worse clinical outcome [5,6]. However, it remains unclear whether a restrictive transfusion threshold is also suited for neurocritical care patients. Studies including patients with subarachnoid hemorrhage (SAH) [7-9] or traumatic brain injury (TBI) [10-12] provide evidence that low $\mathrm{HB}$ is associated with poor functional out- 
come. A recent study in SAH patients reports that higher HB levels $(11.7 \pm 1.5 \mathrm{~g} / \mathrm{dl}$ vs. $10.9 \pm 1.2 \mathrm{~g} / \mathrm{dl})$ were related with better outcome at discharge and at three months [7]. The effects of anemia in patients suffering from supratentorial non-traumatic ICH have not yet been investigated. In the current study, we assessed the impact of anemia on functional outcome and mortality after $\mathrm{ICH}$.

\section{Materials and methods Patients}

We retrieved all patients suffering from supratentorial ICH that were admitted to our stroke unit or neurological ICU between June 2004 and June 2006 from our local stroke database $(\mathrm{n}=247)$. Complete datasets including computed tomography (CT) data, baseline National Institutes of Health Stroke Scale (NIHSS), modified Rankin Scale (mRS) at discharge and laboratory tests were available for 196 patients. ICH was diagnosed by CT. Hematoma volume was calculated from the first CT scan using the $\mathrm{a} \times \mathrm{b} \times \mathrm{c} \times 0.5$ method [13]. Stroke severity on admission was assessed using the NIHSS. Functional outcome at discharge was assessed by the attending physician using the mRS. Functional outcome at three months was assessed by a standardized telephone interview using the mRS or by assessing the final reports after end of rehabilitation. Outcome scores were dichotomized into favorable $(\mathrm{mRS} \leq 3)$ and poor functional outcome (mRS 4-6). The study was approved by the local ethics committee (S$406 / 2009$ ). The data was collected in an anonymized database, therefore the need for informed consent was waived.

\section{HB levels and transfusions}

All HB measurements during hospital stay were extracted from the laboratory database. Routinely, ICU patients have daily laboratory controls, stroke unit patients every other day. In the mean, $7.5 \mathrm{HB}$ values were available for each patient $(\mathrm{SD} \pm 8.0)$. For every patient, $\mathrm{HB}$ on admission and the nadir (lowest value during hospital stay) and mean HB levels (calculated from all available values) were recorded for further analysis. The records of all patients with a nadir of $10 \mathrm{~g} / \mathrm{dl}$ or less were screened for RBC transfusions and the reason for transfusion. At the moment there is no predefined institutional standard for $\mathrm{RBC}$ transfusion in ICH patients. Anemia was defined as a HB level of less than $12.1 \mathrm{~g} / \mathrm{l}$ for women and less than $13.1 \mathrm{~g} / \mathrm{l}$ for men [14].

\section{Statistical analysis}

Distribution of the data was tested using the one-sample Kolmogorov-Smirnov test. Comparisons between groups of patients were made using the chi-squared, Student's $t$ test or the Mann-Whitney $U$ test where appropriate. Mean $\mathrm{HB}$ values in the different outcome categories were compared by using a one-way analysis of variance (ANOVA), post-hoc analyses were performed applying Bonferroni adjustment. Homogeneity of variance was tested using the Levene's homogeneity-of-variance test when applying the Student's $t$ test and ANOVA. Logistic regression was used to create a model to predict poor outcome (mRS 4 to 6 ) at discharge and at three months and in-hospital mortality. The variables age, hemorrhage volume, NIHSS at admission, the presence of intraventricular blood, ICU stay, the need for mechanical ventilation, RBC transfusion, the mean $\mathrm{HB}$ level during hospital stay and admission $\mathrm{HB}$ were entered into the multivariate model. Because of co-linearity of the included variables, a forward stepwise regression analysis was employed to select which of the variables should be included in a regression model to predict the dependent variable. The procedure applied the variables one by one using a criterion such that the F-statistic for the variable to be added must exceed the level of 0.05 . After a variable has been added to the model, the procedure analyzes all included variables and deletes any variable that fails to produce an F-value less than 0.1. After necessary deletions are accomplished, further variable can be added to the model. The procedure terminates when no variable outside the model exceeds the necessary threshold and every variable included is significant. A Cox proportional model was used in order to analyse the risk to develop anemia during hospital stay for both outcome groups. Values of $P<0.05$ were considered statistically significant in all tests. Statistical analyses were performed using the SPSS software package (SPSS 16.0, SPSS Inc., Chicago, Illinois, USA).

\section{Results}

The mean age was 67.1 years (range 29 to 96 , standard deviation (SD) 13.5). The median hemorrhage volume was $26.9 \mathrm{ml}$ (range 0.4 to 383 , interquartile range (IQR) $60.8)$ and 78 patients (39\%) had intraventricular hemorrhage extension. The most frequent etiologies were hypertension (43\%) and $\mathrm{ICH}$ due to oral anticoagulants (20\%); other etiologies included amyloid angiopathy $(16 \%)$ and arteriovenous malformations or cavernous angioma (6\%). For $7.1 \%$ of patients the etiology remained undetermined at the time of discharge.

The mean admission $\mathrm{HB}$ was $13.7 \mathrm{~g} / \mathrm{dl}$ (range 7.4 to 18.4, SD 1.9), the mean HB during hospital stay was 12.6 $\mathrm{g} / \mathrm{dl}$ (range 6.3 to $18.4, \mathrm{SD} 2.1$ ) and the mean nadir $\mathrm{HB}$ was $11.9 \mathrm{~g} / \mathrm{dl}$ (range 6.3 to 18.4, SD 2.3). Only 10 patients (5\%) received RBC transfusions during hospital stay. Mean admission HB of transfused patients was $12.4 \mathrm{~g} / \mathrm{dl}$ (7.6 to 16.3, SD 2.7) and mean nadir HB triggering transfusion was $7.9 \mathrm{~g} / \mathrm{dl}$ (6.3 to 10, SD 1.2). Reasons for transfusion were surgery $(n=5)$, erosive gastritis $(n=1)$, anemia due to chronic nephropathy $(\mathrm{n}=1)$, coronary 
artery disease $(n=1)$ and undetermined $(n=2)$. None of the included patients encountered major bleedings with the need for mass transfusion.

Table 1 shows the univariate analysis of outcome at discharge. Fourty-six (24\%) patients achieved a favorable functional outcome ( $\mathrm{mRS} \leq 3)$ while $150(77 \%)$ had a poor functional outcome (mRS 4 to 6). Patients with poor functional outcome were significantly older (62.5 vs. 68.6 years, $P=0.007)$ had larger hemorrhages $(8.6 \mathrm{vs} .30 \mathrm{ml}, P$ $<0.001)$, and a lower mean HB (13.7 vs. $12.3 \mathrm{~g} / \mathrm{dl}, P<$ $0.001)$ and nadir HB $(13.0$ vs. $11.5 P<0.001)$ during hospital stay. In addition, significantly more patients with poor outcome had intraventricular hemorrhage extension ( $11 \%$ vs. $48 \%, P<0.001)$, developed anemia during hospital stay ( $22 \%$ vs. $56 \%, P<0.001)$, needed ICU treatment (15 vs. $51 \%, P<0.001$ ), and mechanical ventilation ( $4 \%$ vs. $37 \%, P<0.001$ ). There was no significant difference in the median duration of hospital stay (seven vs. six days, $P=0.32$ ) or the number of transfused patients between both groups ( $2 \%$ vs. $6 \%, P=0.302)$.

Figure 1 shows the risk to develop anemia during hospital stay for patients with favorable (mRS 0 to 3 ) versus poor (mRS 4 to 6 ) functional outcomes. Poor functional outcome at discharge was associated with a higher risk of developing anemia throughout hospital stay $(P=0.029)$.

Figure 2 shows patients stratified by mRS category ( 1 to 6), excluding the patients that did not survive the first day in hospital $(\mathrm{n}=17)$. Mean HB levels were significantly different between groups $(14.0,14.0,13.4,13.0,11.9$, and $11.2 \mathrm{mg} / \mathrm{dl}$ for mRS 1 to 6 respectively, $F(5,172)=7.71, P$ $<0.001)$. Post-hoc analysis to compare the different outcome groups separately was performed using Bonferroni adjustment for multiple comparisons; $P$ values are indicated in Figure 2.

We performed a stepwise logistic regression model to predict unfavorable outcome (mRS 4 to 6) at discharge, including age, hemorrhage volume, baseline NIHSS, the

Table 1: Univariate analysis of functional outcome at discharge

\begin{tabular}{|c|c|c|c|}
\hline Variable & $\begin{array}{c}\text { mRS } 0 \text { to } 3 \\
(n=46)\end{array}$ & $\begin{array}{c}\text { mRS } 4 \text { to } 6 \\
(n=150)\end{array}$ & $\mathbf{P}$ \\
\hline $\begin{array}{l}\text { Age (years) } \\
\text { (mean, SD) }\end{array}$ & $62.5(13.4)$ & $68.6(13.1)$ & $0.007^{a}$ \\
\hline Sex (male, n, \%) & $29(63.0)$ & $101(67.3)$ & $0.136^{c}$ \\
\hline $\begin{array}{l}\text { Hemorrhage volume (ml) } \\
\text { (median, IQR) }\end{array}$ & $8.6(24.0)$ & $30(66.4)$ & $<0.001^{b}$ \\
\hline Intraventricular hemorrhage extension ( $\mathrm{n}, \%)$ & $5(10.9)$ & $72(48.0)$ & $<0.001 \mathrm{c}$ \\
\hline $\begin{array}{l}\text { NIHSS on admission } \\
\text { (median, IQR) }\end{array}$ & $4(3)$ & $16(23)$ & $<0.001^{b}$ \\
\hline $\begin{array}{l}\text { Admission HB (g/dl) } \\
\text { (mean, SD) }\end{array}$ & $14.2(1.6)$ & $13.6(2.0)$ & $0.052^{\mathrm{a}}$ \\
\hline $\begin{array}{l}\text { Mean HB }(\mathrm{g} / \mathrm{dl}) \\
\text { (mean, SD) }\end{array}$ & $13.7(1.8)$ & $12.3(2.0)$ & $<0.001^{\mathrm{a}}$ \\
\hline $\begin{array}{l}\text { Nadir HB }(\mathrm{g} / \mathrm{dl}) \\
\text { (mean, SD) }\end{array}$ & $13.0(1.9)$ & $11.5(2.3)$ & $<0.001^{\mathrm{a}}$ \\
\hline $\begin{array}{l}\text { Anemia during hospital stay } \\
(n, \%)\end{array}$ & $10(21.7)$ & $84(56.0)$ & $<0.001^{c}$ \\
\hline $\begin{array}{l}\text { HB measurements ( } \mathrm{n}) \\
\text { (median, IQR) }\end{array}$ & $4(4.3)$ & $5(8.5)$ & $0.22 b$ \\
\hline $\begin{array}{l}\text { Hospital stay (days) } \\
\text { (median, IQR) }\end{array}$ & $7(8)$ & $6(8)$ & $0.32^{\mathrm{b}}$ \\
\hline ICU stay (n, \%) & $7(15.2)$ & $76(50.7)$ & $<0.001^{c}$ \\
\hline Mechanical ventilation ( $\mathrm{n}, \%)$ & $2(4.3)$ & $55(36.9)$ & $<0.001^{c}$ \\
\hline RBC transfusion $(n, \%)$ & $1(2.2)$ & $9(6.0)$ & $0.302^{c}$ \\
\hline
\end{tabular}

a Student $t$-test

b Mann-Whitney-U test

'Chi squared test

HB, hemoglobin; IQR, interquartile range; mRS, modified Rankin Scale; NIHSS, National Institutes of Health Stroke Scale; RBC, red blood cell; $\mathrm{SD}$, standard deviation. 


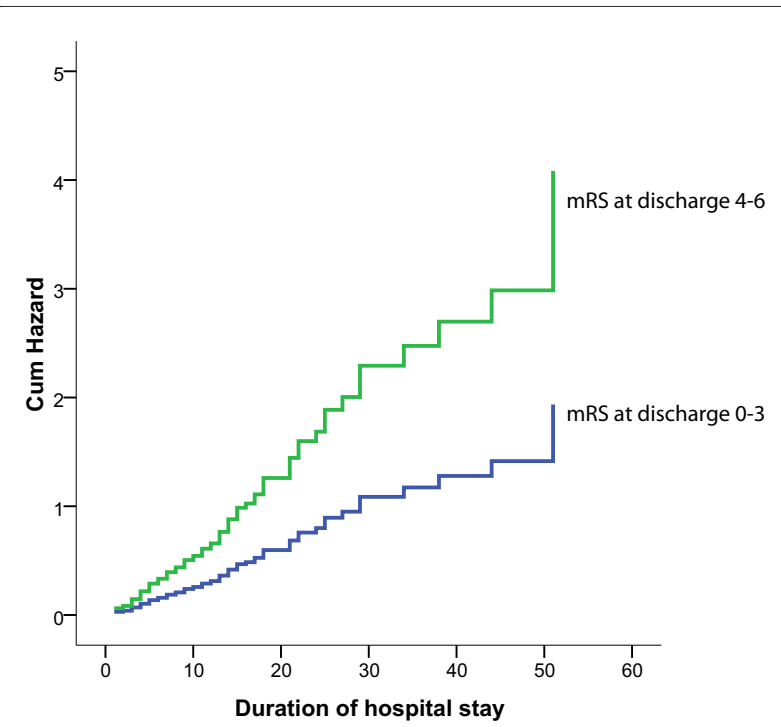

Figure 1 Cumulative hazard to develop anaemia during hospital stay for both outcome groups separately. During their hospital stay, patients with poor functional outcome (modified Rankin score (mRS) 4 to 6) had a higher risk to develop anemia compared with those with favorable outcome at discharge.

presence of intraventricular hemorrhage extension, ICU stay, the need for mechanical ventilation, RBC transfusion and the mean HB level during hospital stay. In the

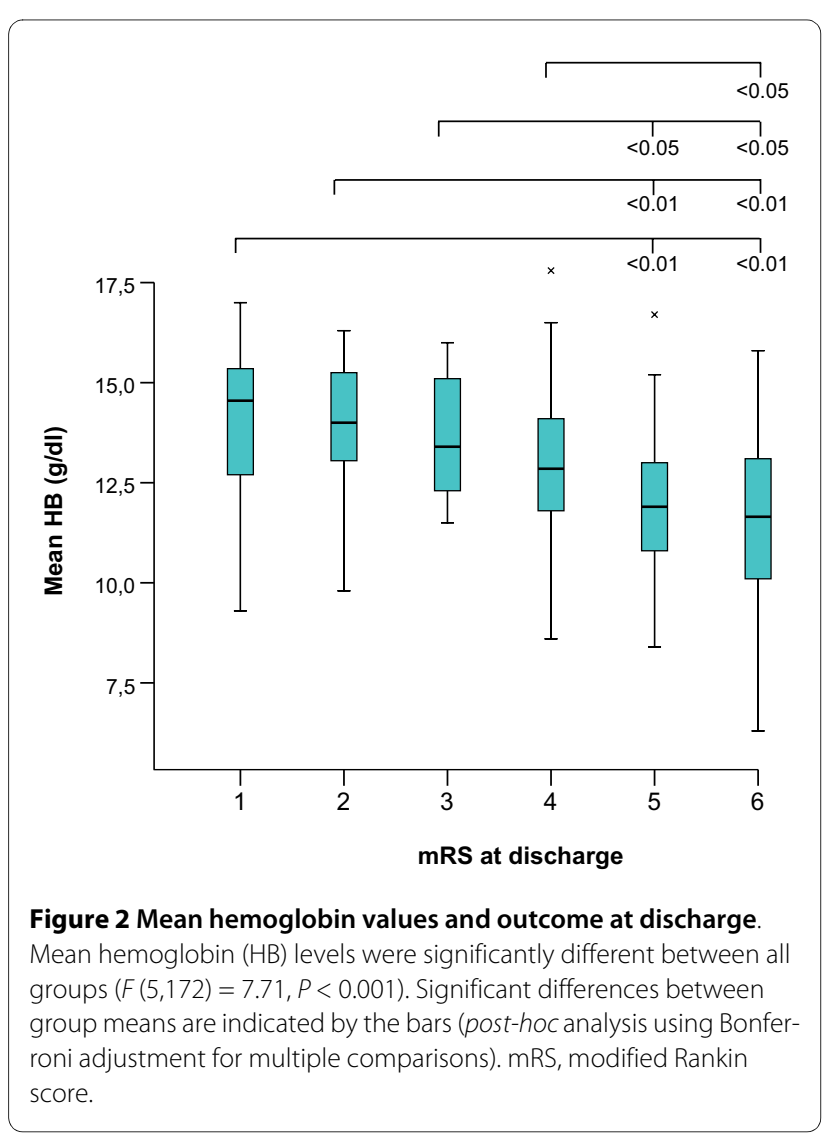

final model, only NIHSS on admission (odds ratio (OR) $1.30,95 \%$ confidence interval (CI) 1.17 to $1.45, P<0.001$ ), presence of intraventricular hemorrhage extension (OR $4.50,95 \%$ CI 1.23 to $15.83, P=0.019$ ), age (per year, OR $1.04,95 \% \mathrm{CI} 1.01$ to $1.08, P=0.021$ ) and the mean $\mathrm{HB}$ (per $\mathrm{mg} / \mathrm{dl}$, OR $0.76,95 \%$ CI 0.59 to $0.97, P=0.027$ ) remained independent predictors for poor functional outcome at discharge (Table 2).

In-hospital mortality was $22 \%$ (43 patients). In univariate analysis, hemorrhage volume, intraventricular hemorrhage extension, admission status, duration of hospital stay, the need for mechanical ventilation and ICU stay, and admission HB levels were associated with in-hospital mortality (Table 3). In the multivariable logistic regression model, NIHSS on admission (OR 1.17, 95\% CI 1.10 to $1.24, P<0.001$ ), hemorrhage volume (per $\mathrm{ml}$, OR 1.02, $95 \%$ CI 1.01 to $1.03, P=0.003$ ) and age (per year, OR 1.05, $95 \%$ CI 1.02 to $1.09, P=0.006$ ) remained independent predictors for in-hospital mortality (Table 4).

Outcome at three months was available for 176 (90\%) patients, 20 patients were lost to follow up. Stepwise logistic regression revealed NIHSS on admission (OR $1.17,95 \%$ CI 1.11 to $1.24, P<0.001$ ), age (per year, OR $1.08,95 \% \mathrm{CI} 1.04$ to $1.12, P<0.001$ ) and the mean $\mathrm{HB}$ (per $\mathrm{mg} / \mathrm{dl}$, OR $0.73,95 \%$ CI 0.58 to $0.92, P=0.007$ ) as independent predictors of outcome at three months (Table 5).

\section{Discussion}

In the current study we found lower HB concentrations to be an independent predictor of poor functional outcome in patients suffering from supratentorial, non-traumatic $\mathrm{ICH}$. Anemia during hospital stay was more likely to occur in patients with poor rather than with favorable functional outcomes.

The design of the current study does not allow for the determination of whether the relation between low $\mathrm{HB}$ levels and functional outcome is causative. Based on the current data, it cannot be excluded that anemia simply represents a marker for severity of illness, rather than causing additional brain injury. Critically ill patients usually receive more intravenous fluids, have more blood drawn for laboratory tests, and more frequently undergo invasive procedures, all factors leading to lower HB concentrations. However, we found lower HB concentrations to be associated with poor outcome, independent of stroke severity, which is the most powerful predictor of outcome of acute $\mathrm{ICH}$.

The absolute difference of mean HB levels between both outcome groups was $1.4 \mathrm{mg} / \mathrm{dl}$, corresponding to a reduction of blood oxygen content of around 10\% ((1.39 × $\mathrm{HB}$ concentration $\left.\left.-\mathrm{O}_{2} \mathrm{Sat} / 100\right)+\left(0.003 \times \mathrm{PaO}_{2}\right)\right)$. A reduction of mean $\mathrm{HB}$ levels from 14 to $11.9 \mathrm{mg} / \mathrm{dl}$ as found for patients with mRS 1 versus 6 respectively 
Table 2: Final stepwise logistic regression model to predict poor outcome (mRS 4 to 6) at discharge. Included variables: age, hemorrhage volume, NIHSS at admission, the presence of intraventricular blood, ICU stay, the need for mechanical ventilation, RBC transfusion and the mean HB level during hospital stay

\begin{tabular}{lccc}
\hline Variable & Coefficient & $\mathbf{P}$ & OR (95\% Cl) \\
\hline NIHSS on admission (per point) & 0.261 & $<0.001$ & $1.30(1.17-1.45)$ \\
$\begin{array}{l}\text { Presence of intraventricular } \\
\text { hemorrhage extension }\end{array}$ & 1.503 & 0.019 & $4.50(1.23-15.83)$ \\
Age (per year) & 0.043 & 0.021 & $1.04(1.01-1.08)$ \\
Mean HB (per mg/dl) & -0.281 & 0.027 & $0.76(0.59-0.97)$ \\
\hline
\end{tabular}

$\mathrm{Cl}$, confidence interval; HB, hemoglobin; mRS, modified Rankin Scale; NIHSS, National Institutes of Health Stroke Scale; OR, odds ratio; RBC, red blood cell.

makes a difference in blood oxygen content of $20 \%$, roughly assuming similar partial pressure of arterial oxygen $\left(\mathrm{PaO}_{2}\right)$ levels. Previous studies in $\mathrm{SAH}$ patients report a comparable magnitude of absolute differences in $\mathrm{HB}$ levels between outcome groups $[7,8]$. Moreover, there is a large body of literature including patients with TBI [1012], SAH [7-9], or ischemic stroke [15-17] suggesting that anemia or even relative anemia may not be tolerated in the setting of acute brain injury. In patients with acute brain injury, physiological compensatory mechanisms such as an increase in cerebral blood flow [18,19] may fail, rendering them more vulnerable to fluctuations in blood oxygen content. Possible mechanisms include impairment of cerebrovascular autoregulation and meta-

Table 3: Univariate analysis of factors associated with in-hospital mortality

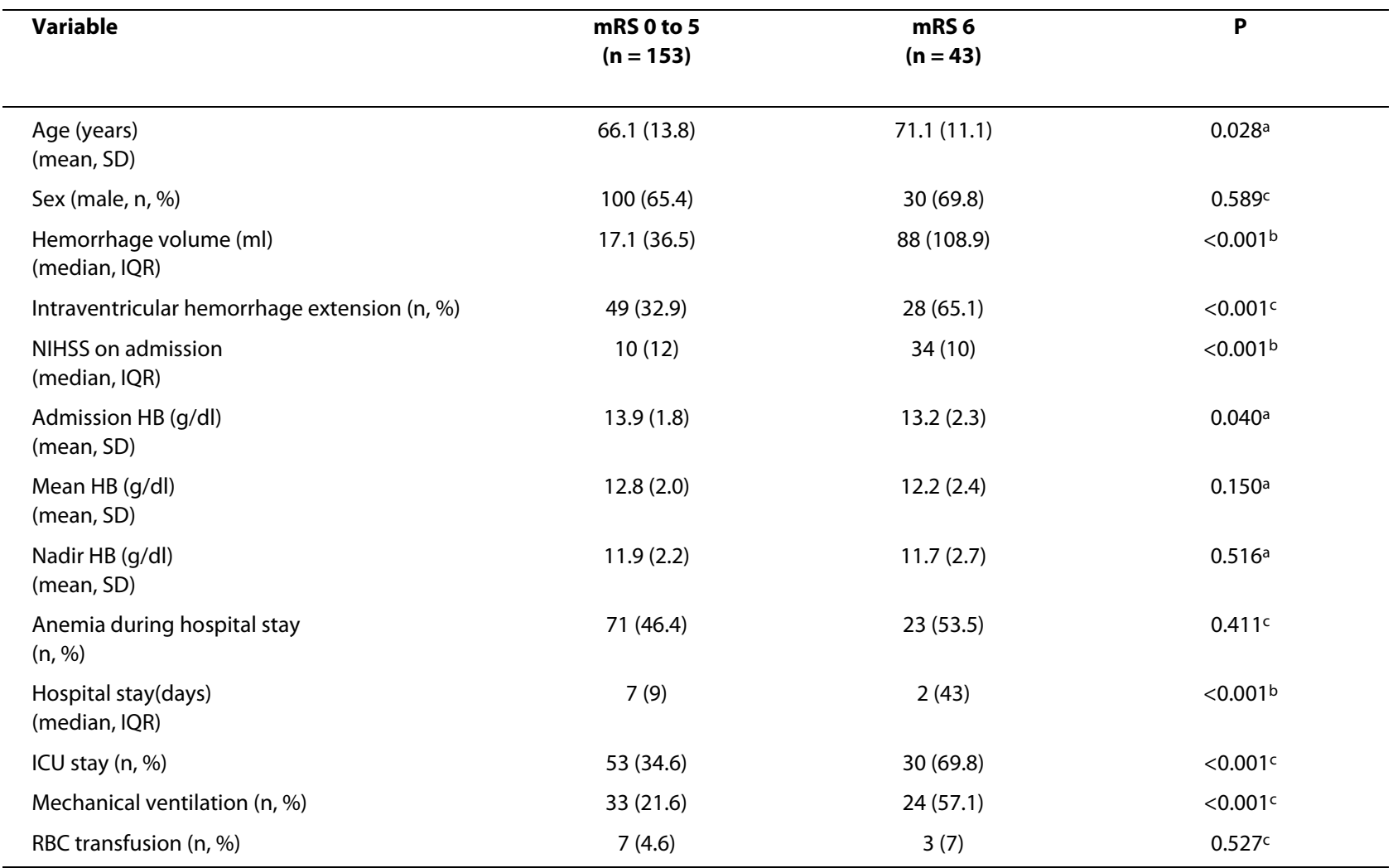

a Student $t$-test

b Mann-Whitney-U test

${ }^{c}$ Chi squared test

HB, hemoglobin; IQR, interquartile range; mRS, modified Rankin Scale; NIHSS, National Institutes of Health Stroke Scale; RBC, red blood cell; $\mathrm{SD}$, standard deviation. 
Table 4: Final stepwise logistic regression model to predict in-hospital mortality. Included variables: age, hemorrhage volume, NIHSS at admission, the presence of intraventricular blood, ICU stay, the need for mechanical ventilation, RBC transfusion and the admission $\mathrm{HB}$

\begin{tabular}{|c|c|c|c|}
\hline Variable & Coefficient & $\mathbf{P}$ & OR $(95 \% \mathrm{Cl})$ \\
\hline $\begin{array}{l}\text { NIHSS on admission (per } \\
\text { point) }\end{array}$ & 0.109 & $<0.001$ & $1.17(1.11-1.24)$ \\
\hline Hemorrhage volume (per ml) & 0.015 & 0.003 & $1.02(1.01-1.03)$ \\
\hline Age (per year) & 0.052 & 0.006 & $1.05(1.02-1.09)$ \\
\hline
\end{tabular}

bolic disturbances of the injured brain [20]. Although some studies have reported intact autoregulation in the perihematomal region in the acute and subacute phase of ICH [21,22], it has recently been demonstrated that global cerebral autoregulation can be impaired in $\mathrm{ICH}$ patients. Additionally, loss of cerebrovascular pressure reactivity was associated with poor outcome [23]. Failure of autoregulation may impede a compensatory increment in cerebral blood flow as response to anemia and thus render ICH patients more vulnerable to a decrease in blood oxygen content.

In addition, animal studies provide evidence that anemic hypoxia may exacerbate primary neurological injury $[24,25]$. Although the concept of an ischemic penumbra in hemorrhagic stroke has increasingly been challenged $[26,27]$, new hypotheses claim the presence of a metabolic penumbra $[28,29]$. Recent studies do not point towards a general lack of oxygen in the perihematomal region, but rather to a changed metabolism [29] with low rates of oxygen use $[26,30]$. However, the exact timing of metabolic and inflammatory processes in the perihematomal zone remains to be elucidated. Moreover, it is conceivable that the metabolic and oxygen demand may change during the course of the disease. So far, there are no studies in humans suffering from acute ICH investigating the effect of low HB levels on the perihematomal zone. Only animal studies in dogs that were exposed to chronic anemia before the induction of experimental ICH provide evidence for an altered brain metabolism in anemic animals $[31,32]$. Although chronic anemic hypoxia promoted a decrease in metabolic demands and an increase in cerebral blood flow, these adaptive responses deteriorated at induction of $\mathrm{ICH}$ [31]. In the acute phase of $\mathrm{ICH}$, anemia was associated with an increased critical threshold of brain oxygenation and progressive deterioration of cerebral hemodynamics.

Although we found an independent association between low $\mathrm{HB}$ and worse functional outcomes, $\mathrm{HB}$ levels during hospital stay were not predictive of in-hospital mortality. Only hemorrhage volume, age and admission status remained independent predictors for in-hospital mortality in the multivariate model. This may be explained by the overwhelming influence of hemorrhage volume on mortality and the fact that $40 \%$ of patients who died, died on the first day of hospital stay. Of interest, admission HB levels differed significantly between both groups in an univariate analysis. This finding is in line with a recent study including almost 700 patients with non-traumatic $\mathrm{ICH}$ investigating the role of anemia on admission (day 1) on the clinical course of acute ICH [33]. Although patients with anemia on admission (25.8\% of patients) were at higher risk of death at 30 days in univariate analysis, this effect did not persist in a multivariate model including hemorrhage volume. Interestingly, the authors report that the presence of anemia on admission was associated with larger ICH volume and thereby hypothesize that the presence of anemia may contribute to hemorrhage growth. Another explanation may be that admission HB levels rather are a marker for poor physiological status on admission. Unfortunately, scores for

Table 5: Final stepwise logistic regression model to predict poor outcome (mRS 4 to 6) at three months. Included variables: age, hemorrhage volume, NIHSS at admission, the presence of intraventricular blood, ICU stay, the need for mechanical ventilation, RBC transfusion and the mean HB level during hospital stay)

\begin{tabular}{lccc}
\hline Variable & Coefficient & P & OR (95\% Cl) \\
\hline NIHSS on admission (per point) & 0.157 & $<0.001$ & $1.17(1.11-1.24)$ \\
Age (per year) & 0.076 & $<0.001$ & $1.08(1.04-1.12)$ \\
Mean HB (per mg/dl) & -0.319 & 0.007 & $0.73(0.58-0.92)$ \\
\hline
\end{tabular}

$\mathrm{Cl}$, confidence interval; $\mathrm{HB}$, hemoglobin; NIHSS, National Institutes of Health Stroke Scale; OR, odds ratio; RBC, red blood cell. 
physiologic illness such as the acute physiology and chronic health evaluation (APACHE) II score were not available due to the retrospective design of our study.

The main limitations of the current study include the small number of transfused patients and the retrospective, observational design that does not shed light on the underlying metabolic processes. However, while the latter was beyond the scope of the current study, further studies invasively assessing the parenchymal metabolic effects of anemia and RBC transfusion in ICH patients seem justified. In the current study, only $10(5.1 \%)$ patients received $\mathrm{RBC}$ transfusions during their hospital stay. RBC transfusion was included as a variable in multivariable models; however, the number of transfused patients was too low to provide solid data on the effect of RBC transfusion on outcome parameters. In order to exclude the possibility that poor outcomes were primarily related to transfusion, rather than anemia, we repeated our analysis after excluding the 10 transfused patients from the multivariate models. In this repeat analysis, mean HB did not remain an independent predictor for poor outcome at discharge but stayed an independent predictor in the model for outcome at three months [see Additional file 1]. However, evidence exists from previous studies including patients with TBI $[10,12]$ or SAH $[34,35]$ that despite some putative beneficial physiological effects, RBC transfusion was associated with additional risks and poorer outcome. In addition, Zygun and colleagues recently have assessed the effect of $\mathrm{RBC}$ transfusion on cerebral oxygenation and metabolism in TBI patients [36]. They report that transfusion of RBC resulted in improved brain tissue oxygenation, but without noticeable effect on cerebral metabolism as measured by lactate-pyuvate ratio. There is currently no data available for $\mathrm{ICH}$ patients.

\section{Conclusions}

In summary, in the current study we found an association between low $\mathrm{HB}$ and poor functional outcome in patients with non-traumatic $\mathrm{ICH}$, as was previously reported for patients with SAH, TBI and ischemic stroke. Although none of the studies in brain-injured patients has so far proven a causative relation between anemia and poor outcome, physiological and observational studies provide evidence for possible detrimental effects of anemia on brain metabolism. However, the potential risk of anemia must be balanced against the potential risk of harm from allogenic RBC infusion. Further trials are needed to investigate the local metabolic effects of anemia and RBC transfusion in $\mathrm{ICH}$ patients.

\section{Key messages}

- Poor functional outcome at discharge and at 90 days was associated with lower mean $\mathrm{HB}$ levels during hospital stay in patients with non-traumatic, supratentorial $\mathrm{ICH}$.

- Based on the currently available data it could not be elucidated if the presence of anemia promotes further brain injury or if it represents a marker of severe illness.

- Further trials are needed to investigate if RBC transfusion in acute ICH may lead to improved outcome.

\section{Additional material}

Additional file 1 Additional logistic regression models. Logistic regression models after exclusion of 10 patients who had received red blood cell transfusions

\section{Abbreviations}

ANOVA: analysis of variance; APACHE: acute physiology and chronic health evaluation; $\mathrm{Cl}$ : confidence interval; CT: computed tomography; HB: hemoglobin; $\mathrm{ICH}$ : intracerebral hemorrhage; mRS: modified Rankin score; NIHSS: National Institute of Health Stroke Scale; OR: odds ratio; $\mathrm{PaO}_{2}$ : partial pressure of arterial oxygen; RBC: red blood cell; SAH: subarachnoid hemorrhage; SD: standard deviation; TBI: traumatic brain injury.

\section{Competing interests}

The authors declare that they have no competing interests.

\section{Authors' contributions}

JD and MS contributed equally and planned and designed the study and performed the statistical analysis. JD wrote the first draft of the manuscript. $\mathrm{PH}$ performed data acquisition. MS, KH, MS, LK, JB and SP critically revised the manuscript. TS contributed to conception of the study and critically revised the manuscript.

\section{Author Details}

1 Department of Neurology, University of Heidelberg, Im Neuenheimer Feld 400, 69120 Heidelberg, Germany and 2Department of Neurology, Comenius University, Mickiewiczova 13, 81369 Bratislava, Slovakia

Received: 22 October 2009 Revised: 18 February 2010

Accepted: 14 April 2010 Published: 14 April 2010

\section{References}

1. Steiner T, Diringer MN, Schneider D, Mayer SA, Begtrup K, Broderick J, Skolnick BE, Davis SM: Dynamics of intraventricular hemorrhage in patients with spontaneous intracerebral hemorrhage: risk factors, clinical impact, and effect of hemostatic therapy with recombinant activated factor VII. Neurosurgery 2006, 59:767-773. discussion 773-764

2. Hemphill JC, Bonovich DC, Besmertis L, Manley GT, Johnston SC: The ICH score: a simple, reliable grading scale for intracerebral hemorrhage. Stroke 2001, 32:891-897.

3. Gujjar AR, Deibert E, Manno EM, Duff S, Diringer MN: Mechanical ventilation for ischemic stroke and intracerebral hemorrhage: indications, timing, and outcome. Neurology 1998, 51:447-451.

4. Diringer MN, Edwards DF: Admission to a neurologic/neurosurgical intensive care unit is associated with reduced mortality rate after intracerebral hemorrhage. Crit Care Med 2001, 29:635-640.

5. Corwin HL, Gettinger A, Pearl RG, Fink MP, Levy MM, Abraham E, Maclntyre NR, Shabot MM, Duh MS, Shapiro MJ: The CRIT Study: Anemia and blood transfusion in the critically ill--current clinical practice in the United States. Crit Care Med 2004, 32:39-52.

6. Vincent JL, Baron JF, Reinhart K, Gattinoni L, Thijs L, Webb A, MeierHellmann A, Nollet G, Peres-Bota D: Anemia and blood transfusion in critically ill patients. Jama 2002, 288:1499-1507.

7. Naidech AM, Jovanovic B, Wartenberg KE, Parra A, Ostapkovich N, Connolly ES, Mayer SA, Commichau C: Higher hemoglobin is associated with improved outcome after subarachnoid hemorrhage. Crit CareMed 2007, 35:2383-2389. 
8. Kramer AH, Zygun DA, Bleck TP, Dumont AS, Kassell NF, Nathan B: Relationship between hemoglobin concentrations and outcomes across subgroups of patients with aneurysmal subarachnoid hemorrhage. Neurocrit Care 2009, 10:157-165.

9. Wartenberg KE, Schmidt JM, Claassen J, Temes RE, Frontera JA Ostapkovich N, Parra A, Connolly ES, Mayer SA: Impact of medical complications on outcome after subarachnoid hemorrhage. Crit Care Med 2006, 34:617-623. quiz 624

10. Carlson AP, Schermer CR, Lu SW: Retrospective evaluation of anemia and transfusion in traumatic brain injury. J Trauma 2006, 61:567-571

11. Van Beek JG, Mushkudiani NA, Steyerberg EW, Butcher I, McHugh GS, Lu J, Marmarou A, Murray GD, Maas Al: Prognostic value of admission laboratory parameters in traumatic brain injury: results from the IMPACT study. J Neurotrauma 2007, 24:315-328.

12. Salim A, Hadjizacharia P, DuBose J, Brown C, Inaba K, Chan L, Margulies DR: Role of anemia in traumatic brain injury. J Am Coll Surg 2008, 207:398-406.

13. Broderick JP, Brott T, Duldner J, Tomsick T, Huster G: Volume of intracerebral hemorrhage: a powerful and easy-to-use predictor of 30day mortality. Stroke 1993, 24:987-993.

14. Beutler E, Waalen J: The definition of anemia: what is the lower limit of normal of the blood hemoglobin concentration? Blood 2006, 107:1747-1750

15. Wade JP, Taylor DW, Barnett HJ, Hachinski VC: Hemoglobin concentration and prognosis in symptomatic obstructive cerebrovascular disease. Stroke 1987, 18:68-71.

16. Huang WY, Chen IC, Meng L, Weng WC, Peng TI: The influence of anemia on clinical presentation and outcome of patients with first-ever atherosclerosis-related ischemic stroke. J Clin Neurosci 2009, 16:645-649.

17. Nybo M, Kristensen SR, Mickley H, Jensen JK: The influence of anaemia on stroke prognosis and its relation to $\mathrm{N}$-terminal pro-brain natriuretic peptide. Eur J Neurol 2007, 14:477-482.

18. van Bommel J, Trouwborst A, Schwarte L, Siegemund M, Ince C, Henny Ch $P$ : Intestinal and cerebral oxygenation during severe isovolemic hemodilution and subsequent hyperoxic ventilation in a pig model. Anesthesiology 2002, 97:660-670.

19. Tomiyama Y, Jansen K, Brian JE Jr, Todd MM: Hemodilution, cerebral O2 delivery, and cerebral blood flow: a study using hyperbaric oxygenation. Am J Physiol 1999, 276:H1190-1196.

20. Vespa PM: The implications of cerebral ischemia and metabolic dysfunction for treatment strategies in neurointensive care. Curr Opin Crit Care 2006, 12:119-123

21. Powers WJ, Zazulia AR, Videen TO, Adams RE, Yundt KD, Aiyagari V, Grubb $\mathrm{RL} J \mathrm{~J}$, Diringer MN: Autoregulation of cerebral blood flow surrounding acute (6 to 22 hours) intracerebral hemorrhage. Neurology 2001, 57:18-24

22. Kuwata N, Kuroda K, Funayama M, Sato N, Kubo N, Ogawa A: Dysautoregulation in patients with hypertensive intracerebral hemorrhage. A SPECT study. Neurosurg Rev 1995, 18:237-245.

23. Diedler J, Sykora M, Rupp A, Poli S, Karpel-Massler G, Sakowitz O, Steiner T: Impaired cerebral vasomotor activity in spontaneous intracerebral hemorrhage. Stroke 2009, 40:815-819.

24. Todd MM, Wu B, Warner DS: The hemispheric cerebrovascular response to hemodilution is attenuated by a focal cryogenic brain injury. $J$ Neurotrauma 1994, 11:149-160.

25. Reasoner DK, Ryu KH, Hindman BJ, Cutkomp J, Smith T: Marked hemodilution increases neurologic injury after focal cerebral ischemia in rabbits. Anesth Analg 1996, 82:61-67.

26. Zazulia AR, Diringer MN, Videen TO, Adams RE, Yundt K, Aiyagari V, Grubb $\mathrm{RL} J \mathrm{~J}$, Powers WJ: Hypoperfusion without ischemia surrounding acute intracerebral hemorrhage. J Cereb Blood Flow Metab 2001, 21:804-810.

27. Miller CM, Vespa PM, McArthur DL, Hirt D, Etchepare M: Frameless stereotactic aspiration and thrombolysis of deep intracerebral hemorrhage is associated with reduced levels of extracellular cerebral glutamate and unchanged lactate pyruvate ratios. Neurocrit Care 2007, 6:22-29.

28. Vespa PM: Metabolic penumbra in intracerebral hemorrhage. Stroke 2009, 40:1547-1548.

29. Zazulia AR, Videen TO, Powers WJ: Transient focal increase in perihematomal glucose metabolism after acute human intracerebral hemorrhage. Stroke 2009, 40:1638-1643.
30. Kim-Han JS, Kopp SJ, Dugan LL, Diringer MN: Perihematomal mitochondrial dysfunction after intracerebral hemorrhage. Stroke 2006, 37:2457-2462

31. Lee EJ, Hung YC: Marked anemic hypoxia deteriorates cerebra hemodynamics and brain metabolism during massive intracerebra hemorrhage. J Neurol Sci 2001, 190:3-10.

32. Lee EJ, Hung YC, Lee MY: Anemic hypoxia in moderate intracerebral hemorrhage: the alterations of cerebral hemodynamics and brain metabolism. J Neurol Sci 1999, 164:117-123.

33. Kumar MA, Rost NS, Snider RW, Chanderraj R, Greenberg SM, Smith EE Rosand J: Anemia and hematoma volume in acute intracerebral hemorrhage. Crit Care Med 2009, 37:1442-1447.

34. Tseng MY, Hutchinson PJ, Kirkpatrick PJ: Effects of fluid therapy following aneurysmal subarachnoid haemorrhage: a prospective clinical study. Br J Neurosurg 2008, 22:257-268.

35. Kramer AH, Gurka MJ, Nathan B, Dumont AS, Kassell NF, Bleck TP: Complications associated with anemia and blood transfusion in patients with aneurysmal subarachnoid hemorrhage. Crit Care Med 2008, 36:2070-2075

36. Zygun DA, Nortje J, Hutchinson PJ, Timofeev I, Menon DK, Gupta AK: The effect of red blood cell transfusion on cerebral oxygenation and metabolism after severe traumatic brain injury. Crit Care Med 2009, 37:1074-1078.

doi: $10.1186 /$ cc8961

Cite this article as: Diedler et al., Low hemoglobin is associated with poor functional outcome after non-traumatic, supratentorial intracerebral hemorrhage Critical Care 2010, 14:R63

\section{Submit your next manuscript to BioMed Central and take full advantage of:}

- Convenient online submission

- Thorough peer review

- No space constraints or color figure charges

- Immediate publication on acceptance

- Inclusion in PubMed, CAS, Scopus and Google Scholar

- Research which is freely available for redistribution
C) Biomed Central 